\title{
On the Influence of Learning Motivation on Classroom Silence in Higher Vocational Colleges
}

\author{
Liyue Zhang \\ Tiangong University, Tianjin, China \\ Email: jenniferhappylife@163.com
}

How to cite this paper: Zhang, L.Y. (2019) On the Influence of Learning Motivation on Classroom Silence in Higher Vocational Colleges. Open Access Library Journal, 6: e5991.

https://doi.org/10.4236/oalib.1105991

Received: December 10, 2019

Accepted: December 15, 2019

Published: December 18, 2019

Copyright $\odot 2019$ by author(s) and Open Access Library Inc.

This work is licensed under the Creative Commons Attribution International License (CC BY 4.0).

http://creativecommons.org/licenses/by/4.0/

\section{(c) (i) Open Access}

\begin{abstract}
Classroom communication is very important for English learning, in the real teaching course, however, the phenomenon of students' silence in English classrooms in higher vocational colleges is very common, which has become a key problem restricting learners' foreign language performance. There are many reasons for this phenomenon, among which learning motivation is very important in the process of learning a second language. It is considered as the main force to continue in the long learning process and an important factor in classroom learning. This research aims to analyze the influence of learning motivation on classroom silence in higher vocational colleges and put forward implications both for teachers and students.
\end{abstract}

\section{Subject Areas}

Education, Linguistics

\section{Keywords}

Learning Motivation, Classroom Silence, Higher Vocational Colleges

\section{Introduction}

\subsection{Introduction to Learning Motivation}

Motivation is operationally defined by Gardner and his associates in a slightly different way for the purpose of measurement, "as consisting of desire to learn the language, motivational intensity, and attitudes towards learning the language. These measured by the Attitude/Motivation Teat Battery or AMTB" [1]. "Learner's motivation in the language classroom can lead to more extensive use of the language and the development of greater language proficiency" [2]. 


\subsection{Classification of Learning Motivation}

Motivation of second language learners can be classified into two groups: one is intrinsic motivation and the other is extrinsic motivation. When the experience of learning language can create the interest and delight, and the reason for learning the language lies within the activity itself, then the motivation may be the intrinsic one. On the contrary, when the reason for learning language is to get something outside the activity itself, for example: dealing with examinations, or obtaining scholarship, the motivation is more likely to be the extrinsic one.

\subsection{Significance of the Research}

In higher vocational colleges, many students think that going to school is for future work, as long as they can graduate. Students are not clear about their learning motivation and why they want to learn English, which leads to the uncertainty of their learning. In addition, due to the poor English level of students, many students lose interest in English learning, and even give up English learning, and they show a lack of initiative and silence in the classroom. This research is to explore the impact of students' learning motivation on their classroom performance.

\section{Research Design and Procedure}

\subsection{Subjects}

This research takes 83 students from a higher vocational college in Tianjin as the research subjects.

\subsection{Instruments}

\section{Questionnaire}

Students from two classes are selected to answer the questionnaire. Before filling, students are informed that they should choose the answer according to the facts and what they choose had nothing to do with their academic grades. And enough time was allotted to answer the questions. The questions in this study was distributed and collected by the questionnaire software "Questioning Star". After the specified time (10 minutes), eighty-seven questionnaires were collected, of which eighty-three were valid. Finally, the collected data were sorted and analyzed by SPSS 25.0. According to the feedback from teachers and the students, the researcher lists five motivations (Table 1).

Table 1. My learning motivation of learning English.

\section{Options}

Q1. Compulsory courses, I just follow the school arrangement

Q2. In order to obtain CET-4 or CET6 certificate

Q3. There is a plan for upgrading the academic degree

Q4. In order to have a better work in the future

Q5. I like English and hope to learn more about the language and culture of English countries. 


\section{Interview}

The purpose of the interview is to make further study about both teachers' and students' deeper thoughts on classroom silence. The researcher designed three interview questions in advance, interviews for students are carried out in a casual and friendly way. In the interview, five students were randomly selected from the research subjects. The questions included their views on the phenomenon of silence and the learning motivation for English learning. The researcher tries to explore whether students' learning motivation will influence their classroom performance.

These five students are different in English levels and classroom performance; they are named S1 - S5 respectively. The following is the outline of the interview questions.

Q1: Do you often keep silent in your English class?

Q2: Do you like English? What's your learning motivation on learning English?

Q3: Will learning motivation influence your classroom performance?

As for the face to face interview section, the interview questions were distributed to them, provide them enough time to think and answer the questions one by one, and the researcher recorded the interviews.

\section{Data Analysis about the Learning Motivation}

\subsection{Discussion about the Questionnaire}

Learning motivation is the most direct factor that affects students' English learning. Due to the different schools in which vocational college students study, their ultimate learning objectives can be broadly summarized into two aspects: first, students can find jobs directly after graduation in the future; the second is that students want to improve their academic qualifications, take the entrance examination and find better jobs. However, most students do not know what their goals are when they enter higher vocational colleges, so their learning motivation is more complicated.

Among the learning motivation options given in Table 2, the most active and passive ones are emphatically analyzed: of all motivations, the most active one is Q5, while Q2, 3 and 4 are all related to academic qualifications or work in real

Table 2. Results of Learning Motivation $(\mathrm{N}=83)$.

\begin{tabular}{cccc}
\hline Options & Subtotal & Ratio & Total proportion \\
\hline Q1 & 55 & $66.27 \%$ & $25.5 \%$ \\
Q2 & 45 & $54.22 \%$ & $20.8 \%$ \\
Q3 & 46 & $55.42 \%$ & $21.3 \%$ \\
Q4 & 43 & $51.81 \%$ & $19.9 \%$ \\
Q5 & 27 & $32.53 \%$ & $12.5 \%$ \\
Number of valid person-times for this topic & & $\mathbf{8 3}$ &
\end{tabular}


life, and the most passive one is Q1, which is entirely due to the school's curriculum arrangement rather than self-will. From the results, we can see that the most passive motivation (Q1), was selected 55 times, accounting for $25.5 \%$. However, the most active option (Q5) was selected only 27 times, accounting for a minimum of $12.5 \%$. In addition, among the other three motivations related to academic qualifications or work, Q3 was selected 46 times at most, accounting for $21.3 \%$ of the total.

From Table 3, we can find that the highest mean is Q1 (0.66), and the lowest mean is Q5 (0.33), it means over half of them are passive to study English, because English class is the "compulsory courses", they have to follow the school arrangement.

Only a few students study English just because they like it, or they want to learn more about culture and language. And the other three factors are in the middle value, which means, "to obtain the certificate", "to upgrade the academic degree", or even "to get a better job" is not the factor that students concerned most. It can be concluded that students' negative psychology in learning motivation leads to students' lack of serious learning attitude, which is the most direct factor leading to classroom silence.

\subsection{Discussion about the Interview}

The first question is the student's feeling of silence in the classroom. Q1, "Do you often keep silent in your English class?"

According to the interview, three of the students said that the class was more active, while two students said that they were not active in the class. One of the students (S5) said, "Although I was very active in the class and took the initiative to answer the teacher's questions, I could still feel the dull atmosphere in the class. As time passed, I became accustomed to this silent atmosphere." Almost all the students said they were silent in class.

In Q2 "Do you like English? What's your learning motivation on learning English", three students (S3, S4) explicitly answered that they were not interested in English, just to pass the examination, while the other three students (S1, S2, S5) said that they were very interested in English, but had poor English performance.

Table 3. Descriptive statistics of learning motivation $(\mathrm{N}=83)$.

\begin{tabular}{cccccc}
\hline \multicolumn{5}{c}{ Descriptive Statistics } \\
\hline Q1 & N & Minimum & Maximum & Mean & Std. Deviation \\
\hline Q2 & 83 & 0 & 1 & 0.66 & 0.476 \\
Q3 & 83 & 0 & 1 & 0.54 & 0.501 \\
Q4 & 83 & 0 & 1 & 0.55 & 0.500 \\
Q5 & 83 & 0 & 1 & 0.52 & 0.503 \\
\hline
\end{tabular}


In Q3: Will learning motivation influence your classroom performance?

All students think that learning motivation has an impact on classroom performance. S1 said, "I study English in order to improve my educational background in the future. If I want to pass the English exam, I have to learn English, so I will listen carefully and speak actively in the classroom." There is another students (S2) said that his purpose of learning English is to find a better job, because the society has a relatively high demand for English now, and most positions require passing CET4 or CET6, so he listens carefully in class, but because of his poor level, when the teacher asks questions, he prefers to keep silent.

The researcher found three points from interviews. Firstly, most students think that their performance in the classroom is silent. Secondly, there are many students interested in English in their learning motivation, but they are often not active in the classroom because of other factors (English level, etc.). Thirdly, learning motivation will affect students' performance in the classroom. Students with clear learning targets and students interested in English will be more active in the classroom. However, it will also be affected by English level or other factors, resulting in the silence in the classroom performance.

\section{Pedagogical Implications}

\subsection{Implications for Students}

1) To learn about future careers and stimulate English learning motivation.

In this research, it was found that higher vocational students do not have a clear plan for the future. Only when they have a clear understanding of their future career needs can they have motivation and learning goal. It can be carried out from the following aspects: first, from their own reality, understand the current social job demand of their major. From the school website, social recruitment platform or by consulting teachers, we can find that there are many requirements for English in recruitment information, thus we can see the importance of learning English. In addition, for students, their main task is to learn, and as higher vocational students should know more about directional learning, because their major is closely related to their future employment.

2) To cultivate confidence and improve English learning efficiency.

Learning English is a hard and long process, and learners need self-confidence. Some studies have proved that under the same conditions, the stronger the self-confidence of learners', the easier they are to succeed. Self-confident learners have more active thinking, stronger creativity, and better memory. On the contrary, people who lack self-confidence are prone to inferiority complex, low self-evaluation, and poor initiative in learning. If you do not have confidence in learning English well and have a negative and pessimistic attitude towards learning English, you will eventually be unable to learn English well.

Confidence is slowly developed. Of course, the influence of classmates and teachers is indispensable in this process. Teachers can guide students to abandon their worries and speak out their ideas boldly. For students themselves, English 
learning itself is a long-term process. On the one hand, higher vocational students should learn to find fun in daily English learning, and choose some movies from native English-speaking countries to watch. They should learn in entertainment, cultivate their sense of language, and believe that they will definitely get something. On the other hand, they should actively participate in English games or dialogue performances in class, encourage themselves every time they speak English, and make progress every time they try. Seize the opportunity to speak English as much as possible, and correctly face the mistakes students make in the process of learning English. Students should have a sense that making mistakes is more meaningful than keeping silent when they speak English.

\subsection{Implications for Teachers}

Improve students' learning interest and motivation during the teaching process.

1) Do not just teach, but ask more questions.

2) Use various methods and materials, such as blackboards, icons, forms, pictures, books, magazines, etc.

3) Use media such as movies, sound recordings or television.

4) Do not indoctrinate all the contents you know into students' minds. Instead, choose the key points and use all kinds of information and forms. Remember that interest often comes from wanting more.

5) Explain why you are interested, what you have done, and what you plan to do in the future.

6) Be passionate when giving lectures, so that students can feel that you believe in what you teach.

\section{Conclusion}

There are both external and internal factors in the influencing factors of students' learning motivation in higher vocational colleges. Internal factors are the dominant factors, and external factors have a certain impact on internal factors. In English teaching, students should have a clear understanding of their own plan. Meanwhile, teachers should mobilize students' subjective initiative in many aspects to eliminate the influence of passive learning motivation on English classroom silence.

\section{Conflicts of Interest}

The author declares no conflicts of interest regarding the publication of this paper.

\section{References}

[1] Gardner, R.C. (1985) Social Psychology and Second Language Learning: The Role of Attitude and Motivation. GB: Edward Arnold, London.

[2] Crandall, J.A. (2000) Language Teacher Education. Annual Review of Applied Linguistics, 20, 34-55. 